\title{
Isolation of RNA from Grains of Medicinal Rice "Njavara" using Improved TRIzol Method
}

\author{
Y. S. Wagh*, M. M. Viji, K. B. Soni, P. R. Jadhav, S. C. Ekatpure, \\ R. V. Manju, Roy Stephen and R. Beena
}

\author{
College of Agriculture, Vellayani, Thiruvananthapuram, Kerala Agricultural University, \\ Kerala, India - 695522 \\ *Corresponding author
}

\section{A B S T R A C T}

\section{Keywords}

Medicinal rice, Njavara rice, Seeds, RNA Isolation, TRIzol, SDS, CTAB

Article Info

Accepted:

20 August 2020

Available Online:

10 September 2020
Isolation of high-quality RNA from seeds is very critical for seed specific gene analysis. An investigation and comparison on the use of CTAB, SDS and TRIzol extraction procedures to extract high-quality RNA from grains of medical njavara rice were carried out in the present study. These protocols either failed to yield RNA or resulted in reduced yield with poor quality of RNA from Njavara rice grains. The starch and secondary metabolites present in njavara rice seeds hindered the isolation and the resuspension of precipitated RNA or contaminated the RNA pellets by co-precipitation. Hence, we modified the TRIzol RNA extraction protocol by addition of $0.5 \% \mathrm{~N}$-lauryl sarcosine, $2 \%$ $\beta$-Mercaptoethanol and 1\% PVP. Highly pure $\left(\mathrm{A}_{260} / \mathrm{A}_{280}\right.$ ratio ranged from 1.9 to 2.0$)$ and intact RNA with a higher yield (up to $500 \mu \mathrm{g} / \mathrm{ml}$ of RNA) could be obtained using modified TRIzol RNA extraction protocol. RNA obtained was testified and efficiently utilized for the cDNA preparation and amplification of Ubiquitin gene.

\section{Introduction}

Njavara rice, indigenous to Kerala, is a unique grain plant in the Oryza genus. It is used in the traditional medicine for the treatment of various diseases related to circulatory, respiratory and digestive ailments (Reshmi and Nandini, 2013). The nutritional and medicinal qualities of Njavara rice are mentioned in the ancient ayurvedic text "AshtangaHridaya", circa 400-500 AD (Murthy, 2001). It is the only cultivar conventionally used in ayurvedic system of medicine in some specific treatments such as
Panchakarma in "Njavara Kizhi" and "Njavara Theppu". Recently, it is reported that Njavara rice has also got anti-cancer properties and an anti-cancer gene associated with 'Bowman-Brisk trypsin inhibitor protein' has been identified (Shareesh, 2007; Shaliniet al., 2012). The flavonoid compound present in njavara rice bran has also shown to have good antioxidant and anti-inflammatory activities (Bakiyalakshmi and Boominathan, 2014). Flavones, a chemotherapeutic agent belonging to a particular group of flavonoids, occur at higher concentration in Njavara rice and have also shown an anti-inflammatory 
effect in carrageenan-induced rat paw edema (Mohanlal et al., 2011).

Molecular and morphophysiological studies have shown that Njavara is a genetically distinct variety of rice with medicinal properties (Shareesh, 2007; Jose et al., 2010; Kumar et al., 2010). It is a short duration rice variety showing asynchronous flowering pattern with other commonly cultivated landraces that prevent cross-pollination and maintains its genetic purity (Sreejayan et al., 2010). There are two types of Njavara rice based on the glume colour viz. black and yellow glumed. These two types are also described in ancient Ayurvedic text AshtangaHridaya (Sootrsthanam Chapter 6 sloka 7-10 Annaswaroopavigyani) (Joseph et al., 2007). Black glumed njavara rice has red seeds with black-shaded grains. Yellow glumed njavara rice also has red colour seeds, but their grains are golden yellow.

The grains of black and yellow glumed njavara rice varieties are rich in flavonoids and other secondary metabolites. Extensive investigation is needed to understand the gene expression patterns and functions during grain filling to harvest stage in Njavara rice. Isolation of high-quality RNA lacking polysaccharides, proteins, phenolic compounds, genomic DNA or secondary metabolites is crucial to undertake the analytical techniques like reverse transcription-polymerase chain reaction (RTPCR), quantitative RT-PCR (qRT-PCR) and complementary DNA (cDNA) library construction etc. Hence, in the present study, an attempt was made for developing a protocol for the extraction of good quality RNA from the grains of black and yellow glumed njavara rice varieties by comparing and modifying the different reported protocols. Njavara rice seeds are rich in high levels of polysaccharides, lipids, proteins and phenolic compounds. Phenols are reported to reduce the yield and quality of RNA (Tai et al., 2004; Groppe and Morse, 1993; Vergara and Ismail, 2007). So far there are no protocols reported for isolating RNA from rice seeds of black and yellow glumed njavara. Plant species, organs and tissues of plants respond differently to the RNA extraction protocols due to the differences in their metabolic activities (Jhala et al., 2015).Hence, in the present study, we compared three protocols based on CTAB, SDS and TRIzol, along with a modified TRIzol method to establish an effective protocol to obtain high quality of RNA with high yield from njavara seeds.

\section{Materials and Methods}

Two types of Njavara medicinal rice namely, black glumed njavara and yellow glumed njavara were grown in pots at the Department of Plant Physiology, College of Agriculture, Vellayani ( $8^{\circ} 5^{\prime} \mathrm{N}$ and $\left.76^{\circ} 16^{\prime} \mathrm{E}\right)$ and the grains were collected at grain filling stage of the crop.

\section{Solutions and reagents}

All the reagents used in the study were of molecular biology grade. Gloves were used at all times during the preparation and changed frequently. Diethyl pyrocarbonate (DEPC) treated water (DTW) $(0.1 \%)$ was used for preparing the solutions. Disposable pipette tips and centrifuge tubes were autoclaved at $121^{\circ} \mathrm{C}$ for $40 \quad \mathrm{~min}$ without diethylpyrocarbonate (DEPC) treatment. Porcelain mortars, pestles and metal objects were wrapped in aluminium foil and baked at $180^{\circ} \mathrm{C}$ for more than $5 \mathrm{~h}$. Plastic and glassware were immersed in $0.1 \%$ (v/v) DTW at $37^{\circ} \mathrm{C}$ overnight and then autoclaved at $121^{\circ} \mathrm{C}$ to inactivate RNases. Mortar and pestle were chilled and wiped with RNAase zap to remove any traces of RNAase before using them to grind the grain samples. 


\section{CTAB RNA extraction protocol (Gambino} et al., 2008)

Grains (100 mg) were ground to a fine powder and collected in RNase-free tubes. The pre-warmed CTAB extraction buffer (1 $\mathrm{ml})$ and $20 \mu \mathrm{l} \beta$-Mercaptoethanol ( $\beta$-ME) was added and mixed by vortexing. CTAB extraction buffer included 2\% CTAB (W/V), 100 mMTris- $\mathrm{HCl}$ (pH 8.0), $20 \mathrm{mM}$ EDTA $(\mathrm{pH} 8.0)$ and $2 \%$ PVP. The samples were incubated at $65^{\circ} \mathrm{C}$ for 20 minutes and vortexed every 5 minutes. An equal volume of chloroform-isoamylalcohol (24:1) was added after incubation. It was mixed and centrifuged for $10 \mathrm{~min}$ at $15,000 \mathrm{~g}$ at $4^{\circ} \mathrm{C}$. The aqueous phase was transferred to a fresh tube and extracted again with an equal volume of chloroform-isoamyl alcohol as before. Onethird volume of $8 \mathrm{M}$ lithium chloride $(\mathrm{LiCl})$ was added to the supernatant and kept overnight at $-20^{\circ} \mathrm{C}$. RNA was pelleted by centrifugation for $10 \mathrm{~min}$. at $15,000 \mathrm{~g}$ at $4^{\circ} \mathrm{C}$. The RNA pellet was washed with $75 \%$ ethanol and dried at room temperature and subsequently resuspended in $50 \mu \mathrm{ldd} 2 \mathrm{O}$.

SDS RNA extraction protocol (Ekatpureet al., 2019)

Grains $(100 \mathrm{mg})$ were taken in chilled mortar and ground to a fine powder using liquid nitrogen. Extraction buffer $(3 \mathrm{~mL})$ was added to homogenate and incubated in a hot water bath for 30 minutes at $65^{\circ} \mathrm{C}$. Extraction buffer contained 150 mMTris base (hydroxymethyl hydrochloride), 4\% (w/v) SDS, $100 \mathrm{mM}$ EDTA ( $\mathrm{pH} 7.5$, adjusted with saturated boric acid), $60 \mu \mathrm{L} \beta-\mathrm{ME}(2 \%, \mathrm{v} / \mathrm{v})$ and 3\% (w/v) PVP-40. The homogenate (approx. $750 \mu \mathrm{l}$ ) was transferred to RNase free $2 \mathrm{ml}$ tube and precipitated using $5 \mathrm{mM}$ potassium acetate $(66 \mu \mathrm{L})$ and absolute ethanol $(150 \mu \mathrm{L})$. Then an equal volume of chloroform-isoamyl alcohol (49:1, v/v) was added and vortexed briefly and centrifuged at $16,000 \mathrm{~g}$ for 20 minutes at room temperature. The supernatant was carefully transferred to a fresh tube and this step was repeated again to remove any suspended cell debris. The supernatant was taken in a fresh tube, added equal volume $(850 \mu \mathrm{L})$ of phenol:chloroform: isoamylalcohol (25:24:1) and vortexed for 10 seconds and then centrifuged at $16,000 \mathrm{~g}$ for 15 minutes at room temperature. The supernatant was collected in a fresh tube and $850 \mu \mathrm{L}$ of chloroform-isoamyl alcohol (49:1, $\mathrm{v} / \mathrm{v}$ ) was added. The tube was briefly vortexed for 10 seconds and centrifuged at $16000 \mathrm{~g}$ for 15 minutes at $4^{\circ} \mathrm{C}$. The supernatant was once again collected and $3 \mathrm{M} \mathrm{LiCl}$ was added to it and then mixed by inversion and kept overnight at $4^{\circ} \mathrm{C}$. The content was then centrifuged at $16,000 \mathrm{~g}$ for 20 minutes at $4^{\circ} \mathrm{C}$. Pellet recovered at this stage was washed twice with 70 percent ethanol. Then the pellet obtained was air-dried at room temperature under sterile laminar airflow and resuspended in $30 \mu \mathrm{L}$ of DEPC-treated sterile distilled water. RNA was quantified in a UV-light spectrophotometer and stored at $-80^{\circ} \mathrm{C}$ until use.

\section{TRIzol method (Chomczynski and Sacchi, 2006)}

Grain samples (100 mg) were ground into a fine powder using liquid nitrogen. $1 \mathrm{ml}$ of TRIzol reagent was added to the powdered samples and mixed gently to homogenize the mixture and incubated at ambient temperature for 5 minutes. Then, the mixture was transferred to a pre-chilled microfuge tube and $0.2 \mathrm{ml}$ chloroform was added. After vigorous shaking, for about 15 seconds it was incubated for 5 minutes at room temperature. The microfuge tubes were kept in ice for 10 minutes and centrifuged at $12,000 \mathrm{~g}$ for 15 minutes at $4^{\circ} \mathrm{C}$. The aqueous phase from the tubes was transferred to fresh microfuge tubes. Hundred percent ice-cold isopropanol of $0.5 \mathrm{ml}$ was added to each tube and kept for incubation at room temperature for 10 minutes. Then the contents in the tubes were 
mixed by inverting the tube slowly and then again centrifuged at $12,000 \mathrm{~g}$ for 10 minutes at $4^{\circ} \mathrm{C}$. After that, the supernatant was discarded carefully and the pellet was washed with $1 \mathrm{ml}$ of $75 \%$ ethanol prepared in DEPC treated water and spun at 7,500 g for 5 minutes at $4^{\circ} \mathrm{C}$. Then the supernatant was removed and the pellet was dried in the laminar airflow chamber. The pellet was then dissolved in $30 \mu \mathrm{l}$ of RNAase free water and incubated for 10 minutes at $55-60^{\circ} \mathrm{C}$. The isolated RNA was stored at $-80^{\circ} \mathrm{C}$ for further use.

\section{Modified TRIzol method}

The ground powder of grains (100 mg) powder was transferred quickly to a $1.5 \mathrm{ml}$ tube with $1 \mathrm{ml}$ TRIzol reagent, $0.5 \%$ N-lauryl sarcosine, 2\% $\beta$-ME and 1\% PVP, mixed completely by vortexing the tube and incubated for $10 \mathrm{~min}$ at room temperature. Then, $0.2 \mathrm{ml}$ chloroform was added and vortexed for about 15 seconds. It was incubated for 5 minutes at room temperature and then centrifuged at $12,000 \mathrm{~g}$ for 15 minutes at $4^{\circ} \mathrm{C}$. The aqueous phase from the tubes was transferred to fresh microfuge tubes. RNA was precipitated with $0.5 \mathrm{ml}$ icecold isopropanol for 10 minutes at room temperature and centrifuged at $12,000 \mathrm{~g}$ for 10 minutes at $4^{\circ} \mathrm{C}$. The pellet obtained was washed with $1 \mathrm{ml}$ of $70 \%$ ethanol prepared in DEPC treated water and sedimented at 7,500 $\mathrm{g}$ for 5 minutes at $4^{\circ} \mathrm{C}$. It was then dried in a laminar airflow chamber and dissolved in 30 $\mu 1$ of RNAase free water and incubated at 55$60^{\circ} \mathrm{C}$ for 10 minutes. The isolated RNA was stored at $-80^{\circ} \mathrm{C}$ for further use.

\section{Qualitative and quantitative analysis of RNA}

The quality of RNA was determined by using agarose gel electrophoresis. The gel was prepared using $1.5 \mathrm{~g}$ of agarose powder dissolved in $100 \mathrm{ml}$ of $1 \mathrm{X}$ TBE. It was cooled down to about $60-65^{\circ} \mathrm{C}$ and ethidium bromide (EtBr) was added to it. RNA samples $(5 \mu 1)$ were loaded in the wells carefully. The voltage was maintained at $5 \mathrm{~V} / \mathrm{cm}$ and the gel was allowed to run till the RNA reached three fourth of gel. The bands were visualized and documented in Gel Doc Unit (Bio-Rad) using Quantity One software.

RNA quantification was done by taking absorbance in UV-visible spectrophotometer (Model-ELICO SL 218, Double Beam, UVVIS, Spectrophotometer, India) at the wavelength of 260 and $280 \mathrm{~nm}$. The absorbance value of 1.0 at $260 \mathrm{~nm}$ indicated

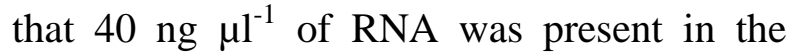
samples. The concentration of RNA in the sample was determined by the formula:

Concentration of RNA $\left(n g \mu 1^{-1}\right)=A_{260} \times 40 \times$ Dilution factor

Where, $\mathrm{A}_{260}=$ Absorbance at $260 \mathrm{~nm}$

The quality of the RNA samples was known from the ratio of the OD values recorded at 260 and $280 \mathrm{~nm}$. The best quality of RNA was referred to by $\mathrm{A}_{260} / \mathrm{A}_{280}$ value between 1.8 and 2.

\section{Preparation of cDNA}

RNA isolated from improved TRIzol method was used for the synthesis of cDNA. The cDNA was synthesized using "Thermo Scientific Verso cDNA Synthesis Kit" according to the protocol provided by manufacturers. The kit contained verso reverse transcriptase which could generate long cDNA strands, RNAase inhibitor to protect RNA templates from degradation and RT enhancer which help to remove DNA contamination. The kit also contained oligo dT primer and Random hexamer. The contents were mixed gently and incubated at $42^{\circ} \mathrm{C}$ for 30 minutes followed by another incubation at $92^{\circ} \mathrm{C}$ for 2 minutes and then the 
cDNA samples were stored at $-80^{\circ} \mathrm{C}$ for further analysis.

\section{Qualitative analysis of cDNA}

The cDNA synthesis was confirmed by standard PCR technique using housekeeping gene Ubiquitin (UBQ5) with gene-specific primers. The final amplified PCR product was separated on agarose gel (1.2\%) and documented using Gel Doc Unit (Bio-Rad) using Quantity One software. The details of primer used (Park et al., 2016) was as follows

\begin{tabular}{|c|c|c|c|}
\hline Genes & Locus ID & Forward (5' to 3') & Reverse (5' to 3') \\
\hline UBQ5 & Os01g0328400 & GAAGTAAGGAAGGAGG & AAGGTGTTCAGTTCC \\
& & AGGA & AAGG \\
\hline
\end{tabular}

\section{Results and Discussion}

Our initial attempt using the three existing methods (CTAB, SDS and TRIzol) to extract total RNA from the plant tissues rich in polysaccharides, polyphenols and protein yielded variable and unsatisfactory results (Table 1 and Figure 1). The yield and quality of total RNA obtained were unexpectedly lower (Table 1). RNA obtained from the CTAB- based method (Gambino et al., 2008) and SDS method (Ekatpure et al., 2019) was found highly degraded and impure. The pellet formed was not completely soluble and RNA recovery was very poor. In addition, there was serious genomic DNA contamination to the isolated RNA. Moreover, the entire procedure was time consuming and labour intensive. With TRIzol method, intact RNA could be obtained, but the quantity obtained was not sufficient and the quality did not qualify for its use in transcriptional level studies. The ratio of absorbance at $260 \mathrm{~nm}$ and $280 \mathrm{~nm}$ was used to assess the purity of RNA (Table 1). Clearly, the efforts with these existing methods were not successful. But among the three methods, TRIzol method was found better as it gave comparatively good recovery. Considering the purity ratio $\left(\mathrm{A}_{260} / \mathrm{A}_{280}: 1.8\right.$ to 2) and the quantity of RNA, further modifications were made in TRIzol method to get better results.

TRIzol (Chomczynski and Sacchi, 2006) is a favourite reagent to extract RNA from different plant materials for the advantage of being simple, relatively short and easy to operate. Total RNA extracted from Njavara rice seeds using TRIzol method gave a low quantity of RNA with a lot of impurities and no DNA contamination. The impurities might be related to the high quantity of carbohydrates and secondary metabolites present in the grains. The compounds like carbohydrates, polyphenols and protein bind or co-precipitate with RNA which degrade the quality and quantity of extracted RNA (Helen et al., 2004; Asif et al., 2006; Wang et al., 2008; Shu et al., 2014). Another problem is the degradation of RNA by ribonuclease (RNase) enzyme. RNase is very stable and difficult to inactivate. Heat can denature ribonuclease but when the temperature is lowered, the enzyme spontaneously refolds into its native active conformation. TRIzol is constituted of guanidine thiocyanate, a strong chaotropic denaturant which completely inactivates the ribonuclease present in the material to be extracted. To strengthen TrizolN-lauryl sarcosine $(0.5 \%) . \quad \beta$ Mercaptoethanol (2\%) and PVP (1\%) were added. PVP aids in the removal of polyphenols (Salzman et al., 1999). It unfolds the RNase at an exceedingly higher rate than the rate of RNA hydrolysis. $\beta$-mercaptoethanol is a reductant which breaks disulfide bonds, thereby facilitating irreversible denaturation of the enzyme (Rashid et al., 2016). N- 
lauroylsarcosine is an anionic surfactant and does not produce excess foaming. It denatures the ribonuclease, inhibit its active site, ensures maximum solubility of nucleic acids and removal of interfering contaminants (e.g. polysaccharides, polyphenols). The chemical agent, diethylpyrocarbonate (DEPC) used to treat plastic wares and water destroys the ribonuclease and translational activity.

Improved TRIzol method developed was found to be rapid and effective in isolating high-quality RNA from Njavara grain samples of $100 \mathrm{mg}$. The quantity obtained was almost double with high purity (Table 1). The quality of the RNA extracted by this method was demonstrated by intact sharp $28 \mathrm{~S}$ and 18S rRNA bands and the lack of RNA degradation on agarose gels (Figure 1). The $\mathrm{A}_{260} / \mathrm{A}_{280}$ ratio ranged from 1.9 to 2.0 , indicating a lack of protein, polysaccharides or polyphenols contamination (Table 1).

Table.1 Quality and quantity of total RNA extracted by four methods from two Njavara medicinal rice grains

\begin{tabular}{|c|l|c|c|c|c|}
\hline & Methods used & $\mathbf{A}_{\mathbf{2 6 0}}$ & $\mathbf{A}_{\mathbf{2 8 0}}$ & $\begin{array}{c}\mathbf{A}_{\mathbf{2 6 0}} / \mathbf{A}_{\mathbf{2 8 0}} \\
\text { Ratio }\end{array}$ & $\begin{array}{c}\text { Quantity } \\
(\boldsymbol{\mu g} / \mathbf{m l})\end{array}$ \\
\hline \multirow{2}{*}{ Black } & CTAB & 0.011 & 0.007 & 1.57 & 132 \\
\cline { 2 - 6 } Njavara & SDS & 0.012 & 0.007 & 1.7 & 144 \\
\cline { 2 - 6 } & TRIzol & 0.017 & 0.01 & 1.7 & 204 \\
\cline { 2 - 6 } & Modified TRIzol & 0.041 & 0.021 & 2.0 & 492 \\
\hline \multirow{2}{*}{ Yellow } & CTAB & 0.009 & 0.006 & 1.5 & 108 \\
\cline { 2 - 6 } & SDS & 0.011 & 0.007 & 1.57 & 132 \\
\cline { 2 - 6 } & TRIzol & 0.019 & 0.011 & 1.7 & 228 \\
\cline { 2 - 6 } & Modified TRIzol & 0.034 & 0.018 & 1.9 & 408 \\
\hline
\end{tabular}

Fig.1 Electrophoresis of total RNA isolated from grains of medicinal rice. A: CTAB Method; B: SDS method; C: TRIzol Method; D: Modified TRIzol method; Lane 1: Black glumed njavara rice; Lane 2: Yellow glumed njavara

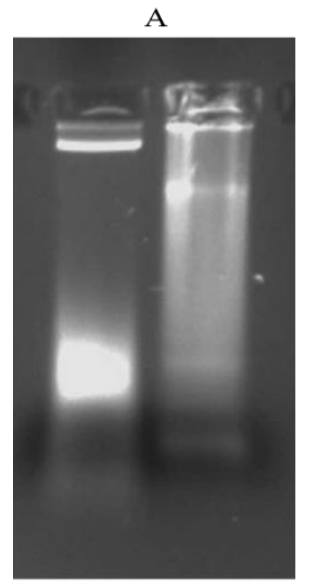

1

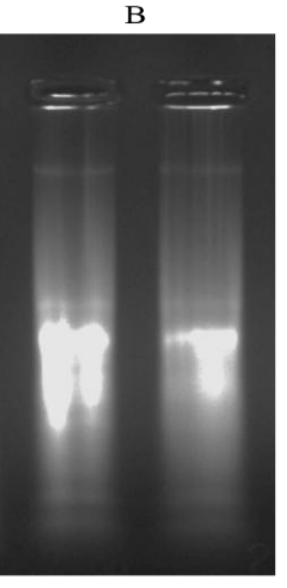

1

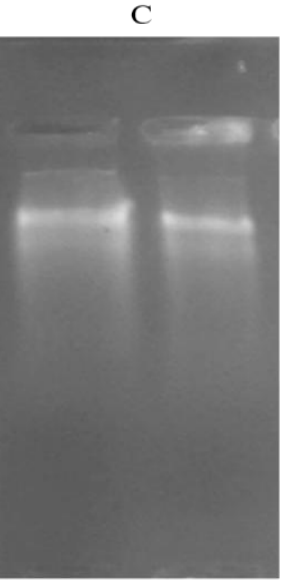

2

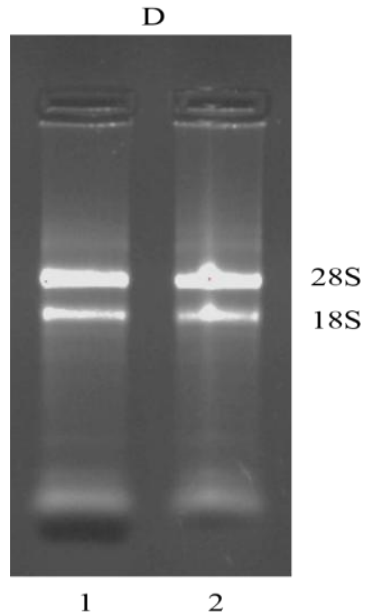


Fig.2 Electrophoresis of PCR products with Ubiquitin (UBQ5) specific primers using cDNA generated from total RNA isolated using modified TRIzol method. (Lane 1: Ladder (100 bp);

Lane 2: Black glumed Njavara; 3: Yellow glumed njavara)

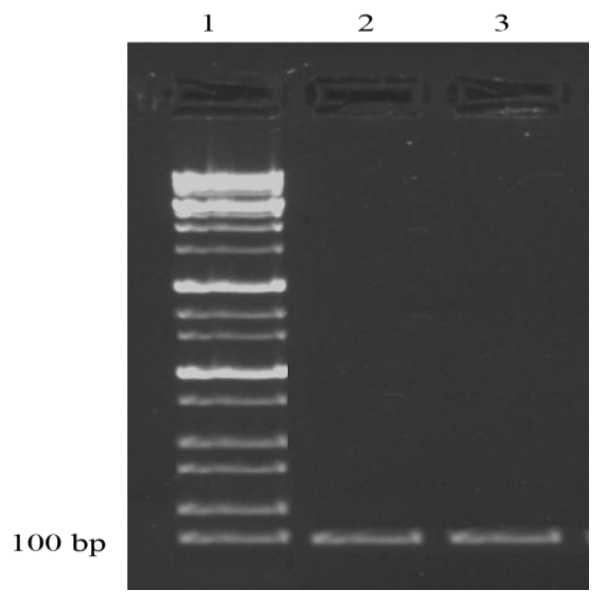

To evaluate the integrity of the extracted RNA, cDNA was prepared and used to amplify a housekeeping gene, Ubiquitin. The synthesis of cDNAs using the extracted RNA and reverse transcriptase enzyme was successful. The target band with expected size of $100 \mathrm{bp}$ was obtained (Figure 2). These results indicate that the improved TRIzol method standardized in this study is effective in the extraction of total RNA for the transcript analysis of gene expression in the grains of njavara rice.

In conclusion these report an improved TRIzol method for high-quality and quantity RNA extraction from black and yellow glumednjavara grains which are rich in starch and secondary metabolites. This method can also be applied to extract RNA from grain/seeds rich in polyphenols and polysaccharides. The effectiveness of this improved method to extract total RNA from grains of njavara rice was confirmed with RTPCR of Ubiquitingene.

\section{Acknowledgements}

The authors are highly grateful to the College of Agriculture, KAU, Vellayani, Kerala, for providing financial support and Department of Plant Biotechnology for providing necessary facilities for the present study. Also, we would thank Regional Agricultural Research Station, Pattambi, Kerala, for making the seed material available to conduct this research.

\section{Author's Contributions}

This work was carried out in collaboration with all authors. Author Wagh conducted the research work, interpreted the data and prepared the manuscript. Author Viji helped to design the experiment corrected manuscript thoroughly. Authors Dr. Soni, Dr. Jadhav, Mr. Ekatpure, Dr. Roy, Dr. Manju and Dr. Beena helped author Wagh Y.S during the experiment and contributed in the manuscript. All authors read and approved the final manuscript.

\section{References}

Asif, M., Trivedi, P., Solomos, T. and Tucker, M. 2006. Isolation of high-quality RNA from apple (Malus domestica) fruit. $J$. Agric. Food Chem. 54(15): 5227-5229.

Bakiyalakshmi, S. V. and Boominathan, M. 
2014. In-vitro pharmacological activity of flavonoid isolated from Njavara (Oryza sativa L.). BioMed. Res. J. 1(1): $1-10$.

Chomczynski, P. and Sacchi, N. 2006. The single-step method of RNA isolation by acid guanidiniumthiocyanate-phenolchloroform extraction: twentysomething years on. Nat. Protoc. 1(2): $581-585$.

Ekatpure, S. C., Soni, K. B., Jadhav, P. R., Lekshmi, R. S. and Alex, S. 2019. Rapid and efficient high quality viral RNA isolation from banana bract mosaic virus infected banana $\mathrm{CV}$. Grand Naine. Int. J. Agric. Sci. 11(6): 8096-8099.

Gambino, G., Perrone, I. and Gribaudo, I. 2008. A rapid and effective method for RNA extraction from different tissues of grapevine and other woody plants. Phytochem. Anal.19: 520-525.

Gehrig, H. H., Winter, K., Cushman, J., Borland, A. and Taybi, T. 2000. An improved RNA isolation method for succulent plant species rich in polyphenols and polysaccharides. Plant Mol. Biol. Rep.18: 369-376.

Groppe, J. C. and Morse, D. E. 1993. Isolation of full-length RNA templates for reverse-transcription from tissues rich in RNase and proteoglycans. Anal. Biochem. 210: 337-343.

Helen, H. T., Pelletier, C. and Beardmore, T. 2004. Total RNA isolation from Piceamarianadry seed. Plant Mol. Biol. Rep. 22: 93-93.

Jhala, V. M., Viralkumar, B. M. and Vrinda, T. S. 2015. Simple and efficient protocol for RNA and DNA extraction from rice (Oryza sativa L.) for downstream applications. Int. Res. J. Biol. Sci. 4(2): 1-6.

Jose, M., Raj, R., Varghese, G. and Thomas, G. 2010. Is Njavara (Oryza sativa L.), the ancient medicinal rice endemic to
Kerala, India, a distinct gene pool? In $28^{\text {th }}$ International Rice Research Conference. Hanoi, Vietnam: IRRI.

Joseph, J., Francies, R. M., Zachariah, G. and Kumar A. V. S. 2007. Characterization of Navara (Oryza sativa L.) a traditional medicinal rice of Kerala for qualitative traits. Indian J. Agric. Res. 41(4): 267271.

Kumar, P. S., Elsy, C. R., Nazeem, P. A. and Augustin, A. 2010. Use of different marker systems to estimate genetic diversity in the traditional medicinal rice cultivar of Kerala. Int. J. Plant Breed. Genet. 4: 89-103.

Mohanlal, S., Parvathy, R., Shalini, V., Helen, A. and Jayalekshmy, A. 2011. Isolation, characterization and quantification of tricin and flavonolignans in the medicinal rice Njavara (Oryza sativa L.), as compared to staple varieties. Plant Foods Hum. Nutr.66: 91-96.

Murthy, K. R. S. 2001. Vagbatta's Ashtanga Hrdayam (Text, English translation, notes, appendix, indices). Varanasi: Krishna Das Academy.

Park, S., Choi, M. J., Lee, J. Y., Kim, J. K., Ha, S. H. and Lim, S. H. 2016. Molecular and biochemical analysis of two rice flavonoid 3'-Hydroxylase to evaluate their roles in flavonoid biosynthesis in rice grain. Int. J. Mol. Sci.17: 1549:DOI: 10.3390/ijms17091549.

Rashid, A., Baldwin, T., Gines, M., Bregitzer, P. and EsveltKlos, K. 2016. A HighThroughput RNA extraction for sprouted single-seed barley (Hordeum vulgare L.) rich in polysaccharides. Plants (Basel). 6: 1-7.

Reshmi, R. and Nandini, P. V. 2013. Therapeutic value of Indian medicinal rice (Oryza sativa L.) Cv. Njavara. Int. J. Food Nut. Sci.2(1): 78-83.

Salzman, R. A., Fujita, T., Zhu-Salzman, K., Hasegawa, P. M. and Bressan, R. A. 
1999. An improved RNA isolation method for plant tissues containing high levels of phenolic compounds or carbohydrates. Plant Mol. Biol. Reptr.17: 11-17.

Shalini, V., Bhaskar, S., Kumar, K. S., Mohanlal, S., Jayalekshmy, A. and Helen, A. 2012. Molecular mechanisms of anti-inflammatory action of the flavonoid, tricin from Njavara rice (Oryza sativa L.) in human peripheral blood mononuclear cells: Possible role in the inflammatory signaling. Int. Immunopharmacol.14: 32-38.

Shareesh, N. 2007. Molecular documentation of Njavara types of rice for cultivar identification. M.Sc. (Ag.) thesis submitted to Kerala Agriculture University, Thrissur.

Shu, C., Sun, S., Chen, J., Chen, J. and Zhou, E. 2014. Comparison of different methods for total RNA extraction from sclerotic of Rhizoctonia solani.
Electron. J. Biotechnol.17: 50-54. Sreejayan, Kumar, U. S., Varghese, G., Jacob, T. M. and Thomas, G. 2010. Stratification and population structure of the genetic resources of ancient medicinal rice (Oryza sativa L.) landrace Njavara. Genet. Resour. Crop Evol.58: 697-711.

Tai, H. H., Pelletier, C. and Beardmore, T. 2004. Total RNA isolation from Piceamariana dry seed. Plant Mol. Biol. Rep.22: 93-93.

Vergara, G. V. and Ismail, A. M. 2007. Total RNA isolation from dry and germinating rice seeds for gene expression studies. Int. Rice Res. Notes. 32: $35-36$

Wang, X., Tian, W. and Li, Y. 2008. Development of an efficient protocol of RNA isolation from recalcitrant tree tissues. Mol. Biotechnol. 38: 57-64.

\section{How to cite this article:}

Wagh, Y. S., M. M. Viji, K. B. Soni, P. R. Jadhav, S. C. Ekatpure, R. V. Manju, Roy Stephen and Beena, R. 2020. Isolation of RNA from Grains of Medicinal Rice "Njavara" using Improved TRIzol Method. Int.J.Curr.Microbiol.App.Sci. 9(09): 2858-2866. doi: https://doi.org/10.20546/ijcmas.2020.909.353 